\title{
BERNSTEIN EN LA ENCRUCIJADA DE LA SOCIOLOGIA DE LA EDUCACION
}

Isidoro Alonso Hinojal

\section{Sentido inicial de la expresión}

Considero la sociología de la educación de Basil Bernstein en la encrucijada de la sociología de la educación actual por varios motivos y en va. rios sentidos que se irán viendo a lo largo de estas líneas. Inicialmente dos son los sentidos mayores que doy a la encrucijada, el teórico y el temático, y a ellos corresponderán los apartados mayores de este trabajo, el 3 y el 4 . Aquí concretaré ambos sentidos mayores y aludiré a otros, si se quiere menores, que también le atribuyo.

Respecto del sentido teórico, habría que hacer unas afirmaciones previas, sobre las que recae hoy acuerdo casi general, que incluye al propio Bernstein, como son:

a) Que la sociología de la educación ocupa una posición estratégica en el campo de la sociología, como la educación misma la ocupa en las tensiones y disputas de las sociedades modernas.

b) Que la sociología de la educación ha tenido y tiene enfoques muy distintos e incluso opuestos, como los tiene la sociología, ligados a las principales corrientes ideológicas. 
c) Que estos diferentes enfoques pueden ser dos, tres o más, pues, en último término, y como dirá Bernstein, todo depende de quién los cuente.

Pues bien, desde el punto de vista teórico trataré de mostrar que Bernstein se apoya en las dos grandes tradiciones, la de Marx y la de Durkheim, y está presente en el renacimiento de una tercera, que proviene de Weber y Mead.

En el sentido temático de la encrucijada, destaca Bernstein por su esfuerzo y realizaciones en los tres niveles o ámbitos típicos del análisis sociológico de la educación: por un lado el estructural o macrosociológico, por otro el interaccional o microsociológico y, entre ambos, el institucional.

Estos son, como digo, los sentidos mayores que doy a la encrucijada, pero hay otros. En lo temático, también Bernstein, que en sus trabajos siempre puso a la familia cerca de la educación, en los últimos sitúa junto a la educación, y con especial énfasis, al trabajo. Con ello hay que incluir a Bernstein entre los sociólogos del triángulo institucional familia-educación-trabajo.

En el sentido teórico, también considero que está Bernstein en la encrucijada en cuanto a las escuelas o tendencias nacionales de la sociología de la educación: británico ante todo, europeo por su inspiración, próximo al grupo francés más destacado, el de Bourdieu, es puente con la sociología de la educación americana, notablemente más distante para él.

Metodológicamente puede considerarse a la sociología de la educación de Bernstein en la encrucijada por las enormes tensiones internas de su trabajo; tensiones de varios tipos: entre niveles, entre teoría y empiría, entre concepciones y reelaboraciones permanentes, etc.

Finalmente y para concluir esta presentación, debo decir, y dejar muy claro, que la encrucijada y posición estratégica en que sitúo a la sociología de la educación de Bernstein la entiendo como exponente teórico, temático y metodológico de la situación y proceder de la sociología actual, es decir, tanto de sus méritos como de sus debilidades, de sus fuerzas y sus flaquezas. De ningún modo se trata de aceptar o intentar consagrar como más o menos definitivas unas ideas y unos procedimientos desiguales, incompletos y en constante modificación, ideas a las que el propio autor prefiere considerar como tesis o programas y no como teorías.

\section{Esquema de los planteamientos teóricos de Bernstein}

Antes de entrar en la sociología de la educación de Bernstein se hace necesario una presentación aunque sea esquemática de su teoría social, dentro de la que se inserta la educativa. No es posible aquí, ni lo voy a intentar, hacer una presentación completa de las aportaciones de un prolífico científico 
social con casi ya un cuarto de siglo de vida productiva. Es preciso ser selectivo y lo seré, aunque las dificultades abundan. Unas son, diría, de carácter cuantitativo, como el volumen de lo publicado y el modo de hacerlo; otras son dificultades directamente ligadas a su teoría, entre ellas: su elevado nivel de abstracción, su constante reelaboración y sustitución conceptual y la dificultad propia de la estructura unitaria de su pensamiento, en cualquier momento en que se le considere.

Entrando en el esquema teórico de Bernstein podríamos destacar en él unos elementos y ciertos procesos; o si se prefiere, sus componentes principales y su dinámica. Entre los elementos señalaré:

- Una preocupación central, la transmisión cultural, que luego será reproducción, y el control social que con ella se ejerce.

- Tres niveles de la realidad social a través de los cuales se produce esa transmisión cultural: el macronivel, la estructura social, vista como estructura de clases, que se apoyan en la división del trabajo y dan lugar a las relaciones de producción. El nivel intermedio, el institucional, el de las agencias de transmisión, entre las que destacan la familia y la educación. El nivel inferior, el del individuo o la persona, conceptos diferenciados en los últimos trabajos de Bernstein, sobre los que se produce la transmisión y el control correspondiente.

- Un elemento constante o hilo conductor en la transmisión, el lenguaje, o mejor, $\mathrm{y}$ teniendo en cuenta sus trabajos recientes, la comunicación simbólica, verbal o no verbal.

Antes de pasar a los procesos, precisaré mínimamente los conceptos fundamentales y su sucesiva reelaboración. La estructura social es siempre en Bernstein estructura de clases, y clases desiguales y en conflicto. Este es el principal elemento de la tradición marxista en Bernstein, que está presente en toda su elaboración teórica. Como respuesta a las críticas a su deficiente definición de las clases sociales, nos dirá en una de sus últimas obras que «las relaciones de clase constituyen desigualdades en la creación, distribución, legitimación y reproducción de valores materiales y simbólicos que surgen de la división social del trabajo»'.

Inicialmente no hay en Bernstein más que dos clases sociales que llamará «clase media y niveles asociados» y «clases trabajadoras». Posteriormente precisará mucho más y distinguirá: la clase dirigente, que mantiene una relación directa con la producción e indirecta con la reproducción cultural y con la educación en particular; en las clases medias diferencia las viejas clases medias, las que son «categorías de la división del trabajo productivo», de las nuevas clases medias, que lo son del control simbólico.

' Bernstern, B., Class, Codes and Control. London, Rouletdge and Kegan Paul, 1977, vol. 3, pág. viii. (En lo sucesivo C.C.C., 3). 
Estas nuevas clases medias resultan a su vez diferenciadas en razón de la progresiva diferenciación del trabajo en el mundo del control simbólico. Bernstein especifica hasta cinco tipos de agentes en el ámbito simbólico: creadores, reguladores, transmisores, ejecutores y reparadores. La conciencia de las clases trabajadoras estará, precisamente, menos dominada por el modo de educación que por el modo de producción, a semejanza de la clase dirigente y a diferencia de las nuevas clases medias. Estas, las nuevas clases medias, ocuparán una posición y jugarán un papel crucial entre las otras clases y entre la producción económica y la transmisión cultural, como veremos.

Respecto a una de las agencias de transmisión, la familia, es conocida la tipología de Bernstein diferenciando la familia centrada sobre las personas de la familia centrada sobre las posiciones, así como la relación de estos tipos con las diversas clases sociales. No es, en cambio, tan conocida la distinción de cuatro contextos dentro de la institución familiar, que son críticos para el proceso de socialización. El contexto regulador o normativo, el instruccional o formativo, el imaginario o innovador y el interpersonal y afectivo.

Ya apunté antes la distinción que hace Bernstein entre individuo y persona, correspondiendo, respectivamente, a una solidaridad orgánica individualista, la que consideró Durkheim con referencia a la vieja clase media que él conoció, y a una solidaridad orgánica personalista, actual, que Durkheim no conoció. Individuo y persona son productos diferentes de socializaciones diferentes. El llamado individuo presenta una personalidad más rígida y más rígidamente identificada con sus roles sociales; la persona, en cambio, tiene una personalidad más flexible y presenta una más ambigua identificación de roles.

Las elaboraciones y sucesivas reelaboraciones conceptuales en torno al lenguaje son las más constantes y complejas. Nos limitaremos a enumerar las sucesivas parejas de conceptos, por otra parte los más criticados de su teoría.

En su primer trabajo publicado ${ }^{2}$ establece Bernstein la dicotomía lenguaje público-lenguaje formal. Esta pareja es sustituida en 1962 por la más conocida de códigos elaborados y restringidos. En un importante artículo de $1973^{3}$ complica más las cosas al añadir, (no sustituir), a los códigos lingüísticos las variantes del discurso, también de dos tipos, elaborados y restringidos y en relación compleja con aquéllos.

Mostraré ya, aunque también esquemáticamente, cómo y en qué dirección se opera el proceso de transmisión cultural, por intermedio de la familia y la educación.

2 BERNSTEIN, B., "Some sociological determinants of perception", British Journal of Sociology, vol. IX (1958), págs. 159-74. (Reeditado en Class, Codes and Control, London, Paladín, 1973, págs. 43-60. En lo sucesivo C.C.C., 1.)

"BERNSTEIN, B., "Social class, language and socialization", Current Trends in Linguistics, vol. 12, Mouton Press, 1973. (Reeditado en C.C.C., 1, págs. 193-213.) 
En una primera versión, a la vez la más conocida y criticada, y hace ya mucho desechada por Bernstein, el proceso se desarrollaría así:

- Hay dos tipos de lenguajes, de código restringido uno y de código elaborado otro. Aquél limitado y dependiente del contexto interaccional; éste más complejo, independiente del contexto y capaz para el razonamiento abstracto.

- La clase media usa ambos, mientras la clase trabajadora sólo usa el restringido, una y otra en razón del respectivo tipo de relaciones sociales en que participa y que viene determinado, a su vez, por la división del trabajo.

- La familia de clase media es del tipo centrado en las personas y socializa con el lenguaje de código elaborado, mientras la familia de clase trabajadora es del tipo centrado en las posiciones y lo hace con el lenguaje de código restringido.

- Pero resulta que las instituciones educativas funcionan con el código elaborado, luego los niños de clase trabajadora tienen más dificultades en la escuela, y, como consecuencia, generan unas actitudes menos favorables hacia ella. Ahí radicará su déficit lingüístico.

Una segunda versión, ésta aceptable para Bernstein, complicaría el proceso aumentando los elementos y rompiendo el determinismo. Los elementos del modelo complejo incluirían, junto a los dos tipos de familia, los cuatro contextos socializadores citados, y junto a los códigos lingüísticos las variantes del discurso. Pero lo más notable en este segundo modelo es que se rompería el determinismo, porque las influencias entre los elementos no serían uni sino multidireccionales, aunque con direcciones más probables. (Los dos tipos de familia se dan en cada clase social, pero en las clases medias se encuentran más frecuentemente las centradas sobre las personas; ambos códigos pueden ser generados en uno y otro tipo de familias, pero el restringido es más frecuente en las centradas en las posiciones; no hay correspondencia entre códigos lingüísticos y variantes del discurso, pero ambos son restringidos o elaborados.) Roto el determinismo, el modelo es más real y capaz de dar cuenta del cambio.

A efectos didácticos podría resumir el modelo teórico de Bernstein de esta forma: ciertas realidades estructurales, clases, poder e ideologías, a través de ciertas agencias de transmisión y control cultural, familia y escuela principalmente, determinan en el individuo ciertas reglas de comunicación y formas de conciencia en razón de que se las haya dotado de unos códigos lingüísticos y otros. Pero como esas estructuras instrumentales básicas, los códigos, son de naturaleza social y resultado de la posición de clases de las agencias transmisoras (y base para el mantenimiento de la estructura de clase mediante la función de control), resulta que quedan relacionados y reforzados mediante 
la transmisión cultural los componentes de la estructura en los distintos niveles, desde las clases sociales hasta el comportamiento personal. La transmisión tiende así a ser reproducción.

\section{La sociología de la educación de Bernstein}

A pesar de la persistencia en Bernstein de sus principales preocupaciones y líneas de investigación, y a pesar de que la educación está desde el principio entre esas constantes, al ocuparnos de ella debemos apoyarnos especialmente en sus últimos trabajos. El giro institucional de la familia a la educación lo reconoce el propio autor, quien lo refleja en los subtítulos de los dos volúmenes de la colección titulada «Class, Codes and Control», el primero y el tercero, que dedica a sus trabajos teóricos; si en el primero precisa «estudios teóricos hacia una sociología del lenguaje», el último concreta «hacia una teoría de la transmisión educativa»:

Al comienzo de uno de sus más importantes artículos, incluido precisamente, y suponemos que no por casualidad, en los dos volúmenes, afirma: «Cómo una sociedad selecciona, clasifica, distribuye, transmite y evalúa los conocimientos escolares refleja, a la vez, la distribución del poder y los principios del control social.» Por eso estos temas «deben constituir un área primordial de interés sociológico" ${ }^{4}$.

A mediados de los años sesenta, en que empiezan a aparecer sus trabajos especialmente educativos, y en los que él reconoce el cambio de acento de la familia a la educación como institución transmisora, el gran tema en la sociología de la educación era el de la igualdad o desigualdad social ante la educación. Bernstein se incorpora al gran debate desde las aportaciones de su trabajo anterior y sociolingüístico, en la modalidad del déficit lingüístico.

Sin duda este tema constituye la parte más confusa y conflictiva de la teoría de Bernstein, por coincidir en él, junto a las propias ambivalencias del autor, ciertas interpretaciones simplistas de sus ideas, una fuerte carga ideológica sobre el tema e incluso la ocasión para que se manifestaran en la disputa claros prejuicios etnocéntricos (como ocurre en la disputa con el americano Labov).

Más que reproducir aquí episodios de la disputa resumiré la posición reciente de Bernstein sobre el tema. Reaccionando y respondiendo a sus críticos, precisa la cuestión y expone su punto de vista ante ella.

Considera la teoría del déficit «como una serie de proposiciones que pretenden explicar el fracaso escolar a base de rasgos superficiales de la familia y la comunidad a que pertenece el niño». A los partidarios de esta teoría podría

"Bernstein, B., "On classification and framing of educational knowledge", en Young, M. F. D. Knowledge and control. London, Collier McMillan, 1971. (Reeditado en C.C.C., 1, págs. 227-256, y en C.C.C., 2, págs. 85-115.) 
llamárseles, dice, «genetistas abstractos» ${ }^{5}$. Para Bernstein el meollo de la cuestión está en otra parte. La clase social dominante actúa decisivamente sobre las instituciones encargadas de la reproducción cultural, entre ellas sobre la educación, pero no para forzar una transmisión igualadora, sino reproductora. Desde este punto de vista, dice, los niños de las clases trabajadoras están en desventaja crítica.

No se trata de que dichos niños procedan de medios e instituciones patológicos, sino de que: «la clase social es una categoría fundamental de exclusión» que actúa de varios modos a través de la escuela y sus formas de transmisión cultural ${ }^{6}$. Por eso las recomendaciones para la política no las hará Bernstein en el sentido en que algunos las han tomado, hacia la aculturación de los niños pobres, sino hacia la reestructuración y adaptación de la propia educación.

De aquí la dura crítica que hace Bernstein de la educación compensatoria en su difundido artículo «Education cannot compensate for society» ${ }^{7}$. Crítica que podría resumirse en los siguientes puntos: no se puede hablar de compensar de algo, de educación en este caso, cuando no se ha proporcionado adecuadamente; la llamada educación compensatoria acentúa excesivamente el papel de los primeros años del desarrollo y la educación, cuando es necesario tomar en cuenta el desarrollo posterior y tener de la educación una idea de conjunto y sistemática; finalmente, es un peligro, o un engaño, desviar la atención fuera de la escuela, antes de buscar todas sus potencialidades reales.

Hasta dónde es posible separar los niveles o ámbitos educativos señalados, pasemos al intermedio o institucional, y para ello tendremos que apoyarnos en los trabajos de la primera parte del volumen tercero de «Class, Codes and Control». Precisamente estos trabajos son considerados como la fuente de inspiración de la llamada «nueva sociología» y por otros «nuevas direcciones en la sociología de la educación».

En el primero de ellos ${ }^{8}$ trata, en sus propias palabras, de crear un marco conceptual para mostrar las interrelaciones entre familia, grupo de iguales, escuela y trabajo, considerando a la escuela como la unidad central del análisis. Significa también una muestra del desacuerdo de Bernstein con la aplicación de la teoría de las organizaciones a las instituciones educativas. En este sentido pretende poner en el centro del análisis los principios de la transmisión cultural y la estructura de relaciones por la cual se produce.

De hecho es un estudio conceptual y muy formal que se apoya en varias clasificaciones: una cultural, que da lugar a dos órdenes institucionales, uno

Bernstein, B., "Introduction", C.C.C.. 3, pág. 27.

Ibídem, pág. 28.

"BERnStern, B., "Education cannot compensate for society", New Society. número 387 ( 28 febrero 1970).

"Bernstern, B., "Sources of consensus and disaffection in education", en C.C.C. número 3. págs. 37-49. 
el orden instrumental y otro el expresivo; otra actitudinal, en relación a los fines y medios de esos órdenes y a su aceptación o rechazo.

No es necesario descubrir a nadie la presencia de Parsons y Merton en estas clasificaciones y tipología resultante, si bien ellos las aplicarían a otros ámbitos de la realidad. En comentario reciente ${ }^{9}$, el propio Bernstein reconoce estas influencias, así como el sabor funcionalista del conjunto, lo que intenta atenuar afirmando que, en cualquier caso, el análisis plantea más cuestiones de conflicto que de equilibrio.

Digamos algo de ambos tipos de órdenes. El instrumental incluye los conocidos y fundamentales elementos de "curriculum», "pedagogía» y «evaluaciones»; es decir, contenidos, métodos y valoraciones. En el orden expresivo se consideran «conducta», «carácter» y «maneras», conceptos estos últimos apenas definidos por Bernstein.

El orden instrumental, al ser transmitido, divide y jerarquiza a los alumnos en razón de sus habilidades y orientaciones a unas u otras materias, como consecuencia de la jerarquización misma de los conocimientos que impone la sociedad. También el equipo docente resultará diferenciado y jerarquizado en razón de su dedicación a unas u otras materias, aparte la influencia de otras categorías sociales de diferenciación, como sexo, edad y, por supuesto, clase social.

El orden instrumental en las instituciones educativas está ligado, o mejor configurado, por la estructura social, y más concretamente por el proceso económico de producción y la división del trabajo social. Este es, pues, uno de los lazos de unión entre este nivel de análisis y el más amplio, el estructural. En una sociedad en la que predomine una cultura de carácter científico o técnico, este orden instrumental será considerado como el único, o en todo caso el principal, a transmitir por la escuela.

El orden expresivo es en Bernstein, como lo es en Durkheim y en Parson, la base principal para la integración social, en instituciones concretas como es aquí el caso de las educativas, o en la sociedad en general. Pero también el orden expresivo o moral le viene dado a la escuela por la sociedad, o mejor, por los grupos dominantes, que así imponen su orden de integración.

Uno y otro orden, el instrumental que divide y el expresivo que unifica, son fuentes frecuentes de tensión y dan lugar a estructuras escolares diferentes: o bien estratificadas, es decir, con fuertes y jerárquicas delimitaciones de roles, individuos y grupos; o bien a estructuras más indiferenciadas, es decir, con débiles y poco jerarquizadas definiciones. Uno y otro orden institucional incluyen fines y medios para lograrlos, fines y medios que pueden ser aceptados o rechazados por los alumnos, sus familias y los profesores. Con las reacciones de unos y otros y con sus combinaciones, diseña Bernstein una

"Bernstein, B., "Introduction", C.C.C., 3, pág. 4. 
complicada gama de interacciones y formas de organización ligadas a la estructura social, siempre diferenciada por clases sociales.

Este planteamiento a nivel intermedio o institucional se continúa en el trabajo «Ritual in education» ${ }^{10}$, en el que considera los ritos escolares como instrumentos especiales de la organización escolar para la transmisión y el control cultural. Diríase que en este sentido los ritos son una forma de código restringido de comunicación y control no verbal, una «forma redundante de mensajes condensados".

Los ritos escolares se dan tanto en el orden instrumental como en el expresivo, pero es sobre todo éste el que se presta mejor a la ritualización. «Los valores del orden expresivo - dirá Bernstein - son convertidos mediante los ritos escolares en elementos de la estructura social de la escuela.» $\mathrm{Y}$ en otro lugar: «Una de las fuentes principales de control en las escuelas (estratificadas) es la interiorización de su estructura social y el nacimiento y organización de sentimientos evocados por medio de los ritos... ". De este modo, los cambios en la estructura de la escuela y especialmente en su orden expresivo, significarán cambios importantes en la socialización. Al mismo tiempo estos cambios organizativos estarán probablemente en relación con cambios paralelos en la organización de las relaciones de trabajo.

Así, pues, los ritos escolares son mecanismos importantes de la organización escolar, están determinados por la estructura social y condicionan la socialización, reforzando los mecanismos de transmisión cultural. En relación con la organización escolar, cuanto más se aproxime ésta al modelo de institución total, más tenderá a ritualizarse. Lo mismo ocurrirá cuanto más fraccionada y segregada esté internamente. En relación con la sociedad total, la ritualización educativa tenderá a ser mayor cuanto más aislada esté la comunidad escolar y cuanto más predominante sea una ideología política o religiosa en dicha sociedad.

Pero la ritualización se da también en el orden instrumental de los centros educativos, y en este orden destacan los ritos de los exámenes que, una vez más, pueden verse o ponerse en relación con la organización escolar y con la estructura social. A nivel organizativo, cuanto más domine el orden instrumental más favorable se hace la cultura escolar a los exámenes, que se convierten en principal instrumento de separación, jerarquización y control. Por supuesto, también la interacción y el contenido educativo se ven afectados por la ritualización de los exámenes, así como el rol de alumno, eventual examinando, y el de profesor, potencial examinador.

A nivel social, cuanto más se diversifican una sociedad y su economía, más tenderá a diversificarse la educación, y a ritualizarse el orden instrumental, a adquirir predominancia los exámenes. «Se subordinan las necesidades

10 Bernstein, B., C.C.C., 3, págs. 54-66.

"Ibidem, pág. 59 . 
de los alumnos a las exigencias de la división del trabajo a través del sistema de exámenes», dice Bernstein ${ }^{12}$. El orden expresivo, y los ritos correspondientes, por el contrario, pierden fuerza en una sociedad diversificada y pluralista. Los problemas de identidad, valores, etc., que resolvían los ritos escolares impuestos por los adultos, se resolverán ahora por los ritos expresivos que generan e imponen los propios grupos de jóvenes, los alumnos.

Al considerar el tercer nivel o ámbito educativo, el más reducido, el interaccional, hay que apoyarse sobre todo en dos de los trabajos más recientes y difundidos de Bernstein. El primero de ellos ( $«$ On classification and Framing of Educational Knowledge» ${ }^{13}$ ) fue publicado inicialmente en el «reader» de Young, que se considera proclamación de la «nueva» sociología de la educación, y posteriormente incluido por Bernstein en los dos tomos de sus obras teóricas citadas. Esto da idea del carácter central que da su autor a este trabajo. Con palabras retrospectivas del autor, en este trabajo logra construir un «par de conceptos analíticamente operativos a distinto nivel lógico», al nivel de la interacción en el aula y al nivel de la estructura social que condiciona aquélla. Por otra parte, este par de conceptos es aplicable a varias agencias de transmisión cultural, en concreto a la familia y a la educación, lo que permite el análisis de su interrelaciones.

Conceptos con estas características necesariamente tienen que resultar enormemente formales y abstractos, sobre los que recae la fundamental crítica de su alejamiento de la contrastación empírica. Los conceptos son los de clasificación y encuadre ("Classification and framing»). El primero se refiere al grado de consistencia de las delimitaciones, a las fronteras, entre contenidos, es decir, entre los conocimientos educativos. El segundo «al grado de control que los actores, en este caso profesores y alumnos, tienen para la selección, organización y secuenciación de los conocimientos a transmitir y recibir a través de la relación pedagógica» ${ }^{14}$.

Lo importante es ver cómo detrás de las clasificaciones y los encuadres, que significan diferentes formas de transmisión cultural, actúan estructuras de poder y control social, que desde el nivel estructural descienden, a través de las agencias de transmisión, hasta el nivel de la conciencia individual. El poder se refleja y actúa a través de las clasificaciones, es decir, de las separaciones y jerarquizaciones, ya sea de conocimiento, de personas u objetos con sentido. El control, ejercido por ese poder, se refleja en los encuadres, es decir, en el tipo de interacción que mantienen los actores.

Con este par de conceptos pretende también Bernstein emsamblar el tema lingüístico y el educativo, a través de los códigos respectivos. A tal efecto el autor se pregunta: "Si las condiciones sociales que dan lugar a los códigos lingüísticos restringidos son los contextos y relaciones sociales de intimidad,

12 Ibídem, pág. 63 .

13 Véase nota 4.

i4 Véase, por ejemplo, en C.C.C., 3, pág. 89. 
¿cuáles son los contextos y relaciones que dan lugar a los códigos elaborados» ${ }^{15}$, propios de la educación?

La respuesta es que los códigos elaborados se estructuran en la medida en que son fuertes las clasificaciones y los encuadres, es decir, las delimitaciones internas y externas en la transmisión del conocimiento, fundamentalmente en la educación formal. (Precisamente en esas clasificaciones rígidas, en esa compartamentalización de los conocimientos, es donde Bernstein ve uno de los orígenes del saber como propiedad privada.) $\mathrm{Y}$ todo ello, contenido y mecanismos de transmisión, condicionado por la estructura social, es decir, la estructura de clases. Dirá Bernstein: "Mientras la división del trabajo social inevitablemente ejerce su influencia sobre el contenido de la educación, la estructura de clases y su ideología legitimadora regula las clasificaciones y los encuadres de tales contenidos y de su negociación en la educación» ${ }^{16}$. Es decir, del poder y control que con ellos se ejerce.

Los cambios sociales actuales o recientes, desde los tecnológicos a los ideológicos, juegan en favor de una transmisión cultural más flexible, es decir, en favor de unas clasificaciones y encuadres más débiles, lo que significa una socialización más interpersonal y menos interposicional y unas personalidades resultantes más flexibles y adaptables. Pero este movimiento hacia una desclasificación y un desencuadre en la transmisión cultural refleja una crisis social, centrada en la estructura de poder y en los sistemas de control, que es lo que reflejan esas clasificaciones y encuadres.

Los anteriores conceptos y líneas de análisis son aplicados por Bernstein a un ámbito educativo más concreto, el de la educación preescolar, en un artículo reciente, del que sin embargo existen ya tres versiones ( pedagogies: visible and invisible») ${ }^{17}$. Este trabajo, cuya primera versión nació en París y a petición de la OCDE, marca la aproximación, o mejor el intercambio, de Bernstein con el equipo de Bourdieu, que aparece tan claro en la obra reciente del autor que estamos considerando.

Llama Bernstein pedagogía invisible, como contraposición a la visible, a aquella en la que: el control sobre el niño es más bien implícito; el medio escolar ha sido previamente preparado y luego dejado al descubrimiento del propio niño; en este medio preparado el niño goza aparentemente de gran discrecionalidad para sus actividades y relaciones; se pone escaso énfasis en la adquisición de habilidades concretas y los mecanismos de evaluación son difusos.

Con las propias categorías de Bernstein, se trata de una pedagogía caracterizada por una débil «clasificación» y un débil «encuadre». La pedagogía

"Postcript", C.C.C., 1, págs. 261-262.

in Ibídem, pág. 262.

"La primera versión es de 1975 (Studies in the Learning Sciences. París. OCDE) y dos de 1977, una en Karabel and Halsey. Power and ideology and education. New York, Oxford University Press, cap. 30, y otra, ampliada, en C.C.C.. 3, capítulo 6 . 
«es tanto más invisible cuanto más difusos son los criterios y más implícitos los procedimientos de transmisión». El concepto clave de la pedagogía invisible es el de juego, como lo es el de trabajo en la pedagogía visible. En la invisible, todo juego es trabajo y todo trabajo es juego. La pedagogía invisible, en contra de lo que podría parecer, lleva implícita una forma de control, una vigilancia del niño, que es también peculiar: es a la vez invisible y total, en cuanto que relaciona las disposiciones internas del niño con sus actos externos.

Dada la imposibilidad de analizar el tema con detalle, hagámonos dos preguntas sobre él: $1 .^{a}$, dónde se origina esta nueva pedagogía; y $2 .^{a}$, qué implicaciones tiene para las clases sociales en ella implicadas.

La nueva pedagogía se origina en la nueva división del trabajo en la sociedad industrial de clases. En concreto, en la subdivisión de la vieja clase media y la aparición de la nueva clase media. Se origina en el cambio de «hábitos», ya que no de función, de parte de la clase media, la que se ocupa de la transmisión cultural mediante la manipulación simbólica.

Pero estas nuevas clases medias, precisamente por significar un cambio de hábitos y no de función en la estructura de clases, conllevan como tales clases una serie de contradicciones fundamentales que se transmiten a su ideología socializadora y a la pedagogía invisible en que se traduce. Como tal clase social, por una parte está en favor de la flexibilidad y en contra de la rigidez de normas, en favor de la expresión y en contra de la represión, y en favor de las relaciones interpersonales y en contra de las interposicionales. Pero, por otra parte, dicha nueva clase media está sometida a las rigideces de la división del trabajo y a los estrechos márgenes de poder y privilegio que se le conceden como tal clase social intermedia.

Las contradicciones de la nueva clase media se transmiten a su ideología y pedagogía correspondiente. Empiezan las contradicciones en que tal pedagogía, la invisible, es apoyada por esta clase social en los primeros niveles educativos, pero es abandonada, para pasar incluso a apoyar la vieja pedagogía, la visible, en los niveles posteriores y a medida que sus hijos van acercándose al mundo del trabajo.

Respecto de las consecuencias sobre los niños de las clases trabajadoras, la pedagogía invisible, por su mayor flexibilidad, puede parecer que, en principio, permite incluir la cultura de estas clases en la experiencia escolar. De hecho no es así, pues, de un lado, resulta incomprensible para los padres de esta clase social, y por otra, esta pedagogía da más poder relativo a los maestros, que siguen consagrados a la cultura dominante, respecto de los padres. De hecho, «el argumento central de este trabajo es que ambas pedagogías, conflictivas entre sí, han nacido de las distintas facciones de la clase media, y la institucionalización acrítica de una y otra no supondrá ventaja alguna para la baja clase trabajadora» ${ }^{18}$.

18 "Introduction", C.C.C., 3, pág. 19. 
Este aspecto del análisis de Bernstein se parece no sólo al realizado por el equipo de Bourdieu, en concreto al hecho por Chamboredon en «L'école maternelle», sino también a la crítica de la escuela abierta del marxista Gintis ${ }^{19}$.

En el trabajo que comentamos vuelve Bernstein al tema de los exámenes, aspecto de la organización escolar siempre importante como mecanismo de control. Aquí, además, lo presenta como manifestación singular de las contradicciones de la pedagogía invisible. Las prácticas evaluadoras de una y otra pedagogía son opuestas en sus planteamientos, pero no siempre, como veremos, en sus implicaciones. En la pedagogía visible, las evaluaciones se hacen con criterios claros, por procedimientos concretos, y se reflejan en información cuantificada; por eso la evaluación resulta comprensible para todos, incluso para los padres de clase trabajadora, comparable entre niños y entre centros, e indiscutible, dada su supuesta objetividad. En la pedagogía invisible, las evaluaciones son múltiples, con criterios difusos, y difíciles de comparar; como consecuencia, resultan no comprensibles, incluso para los padres de clase media, no comparables, pero también indiscutibles, dada su complicación y supuesta tecnificación.

Diré, finalmente, que a nivel de configuración histórica de los sistemas educativos, así como la vieja pedagogía, la visible, la de la vieja clase media, fue institucionalizada en las escuelas públicas, la pedagogía invisible ha sido institucionalizada sobre todo en el sector privado. Y como el sistema de transmisión o reproducción de la nueva clase media, de la que procede la nueva pedagogía, no es la propiedad económica, sino la simbólica, la competición de esta clase social por centros selectos, más y más eficaces en esa transmisión, se acentúa enormemente y dinamiza el sector privado del sistema educativo.

Con "Class and Pedagogies" creo haber completado la presencia y aportaciones de Bernstein en los tres niveles o ámbitos de la sociología de la educación, pues este trabajo tiene el propósito expreso de mostrar cómo las relaciones cruciales en la reproducción cultural son las que se establecen entre transmisor y receptor, profesor y alumno. Estamos especialmente con este trabajo en el nivel más reducido, en el interaccional.

Señalaba al principio otro aspecto de la teoría de Bernstein que lo sitúa también en la encrucijada, el ser uno de los sociólogos del triángulo institucional. Es decir, de los que apoyan su teoría, y en ella dan una importancia preferente, a la institución familiar, la educativa y la productiva. Esta importancia teórica va más allá del análisis de esas instituciones en sí; se ocupa sobre todo de sus interrelaciones y, a través de ellas, de la interpretación de los fenómenos sociales y centrales.

19 Chamboredon, "Le métier d'enfant", en Revue Française de Sociologie, vol. XIV (1973), págs. 295-335. Gintis, H., "The Politics of Education", en Monthly Review, vol. 23 (Dec. 1973). 
Es éste otro aspecto de la confluencia Bernstein-Bourdieu; ambos tienen entre sus últimas publicaciones sendos trabajos sobre las organizaciones de producción y sus relaciones con las educativas y familiares.

Desgraciadamente no hay tiempo aquí para el análisis comparativo, ni siquiera para la consideración completa del artículo de Bernstein titulado: «Aspects of the relations between education and production" ${ }^{20}$. Pretende Bernstein aplicar a la producción los conceptos claves aplicados a la educación y poner en relación los resultados de dichas aplicaciones. Esos conceptos son ante todo los de clasificación y encuadre. El primero se referirá a la delimitación y jerarquización de los diversos agentes de la producción, como pueden ser el personal cualificado, no cualificado, técnico, etc., y nos presentará unas clasificaciones, es decir, delimitaciones, fuertes o débiles. Los encuadres se refieren a las relaciones y comunicaciones entre esas categorías en la acción productora, y también pueden ser fuertes o débiles. Las clasificaciones tienen que ver más con lo que se produce y los encuadres con cómo se produce.

Por este procedimiento llega Bernstein a identificar cuatro formas históricas de control ideológico de la producción, que pueden ponerse en relación con otras tantas teorías predominantes en las respectivas etapas históricas. Son éstas el taylorismo, la teoría de las relaciones humanas y la del sistema sociotécnico. La cuarta forma de control se conectaría con la teoría de la democracia industrial, apoyada en los trabajadores y opuesta a las tres anteriores.

Al comparar los tipos de regulación de la producción y de la educación, encuentra Bernstein correspondencia entre regulaciones rígidas en uno y otro sector. Pero existen desajustes y contradicciones en esa correspondencia, que precisamente dan a la educación esa relativa autonomía en su dependencia del sistema productivo. Se rechaza, pues, el principio de total correspondencia entre producción y educación, que mantienen algunos autores, tanto funcionalistas como marxistas. «La educación ha sido muy poco eficaz en la creación de una fuerza de trabajo dócil y diversificada. Por otra parte, la escuela hoy es incapaz de disciplinar a la juventud», dice Bernstein ${ }^{21}$.

Esta relativa autonomía de la educación respecto de la producción, paralela a la existencia entre base y superestructura, tiene múltiples e importantes implicaciones para Bernstein. Apuntaré simplemente algunas:

a) Pone de manifiesto, en primer lugar, que es distinto, o al menos diferenciable, el «poder dominante», el de la producción, del «control dominante», el de la educación, o de la reproducción cultural.

b) La relativa autonomía de la educación confiere a sus principios y valores, tales como el de objetividad, neutralidad, altruismo, dedica-

20 Bernstein, B., C.C.C., 3, cap. 8.

2 Ibidem, pág. 188. 
ción, etc., también cierta autonomía, que se transmite de alguna manera a los profesionales que a la educación se dedican.

c) Explica también las desiguales o matizadas relaciones de las clases sociales con la producción y la educación. La clase dominante, y en forma paralela pero opuesta, la trabajadora, tienen una relación directa con la producción e indirecta con la educación. Al revés ocurre con la nueva clase media, y de ahí su peculiar posición respecto a las otras dos.

d) Finalmente, esta parcial autonomía a la vez facilita y se manifiesta en el cambio social y en situaciones históricas en que ha variado la posición relativa de la educación respecto de la economía.

Es inevitable el aludir aquí al trabajo de Bourdieu y Boltanski «Changes in social structure and changes in the demand for education», publicado el mismo año que el citado de Bernstein, $1977^{22}$. Es otro destacado ejemplo de lo que he llamado triángulo institucional. Este trabajo intenta, y creo que logra, mostrar cómo puede perdurar la estructura de dominación de clases a pesar de que varíe la posición de alguna o todas esas clases respecto de las distintas formas de capital, económico, social y cultural. Esta, diríamos, «permanencia en el cambio» se logra mediante las estrategias de reconversión de un capital en otro por parte de las distintas clases sociales. Pero lo importante aquí es que estas estrategias de reconversión «han hecho de la educación al menos el requisito formal para la apropiación del beneficio» en la nueva situación. Las estrategias de reconversión pasan por la educación y equivalen a estrategias de reproducción cultural y social.

\section{Criticas a la sociología de la educación de Bernstein}

Como ocurre con cualquier otro autor, Bernstein no puede ser entendido sin tomar en consideración a sus críticos. Los trabajos de Bernstein han recibido, a la vez, una gran difusión y aceptación, abundantes críticas y no escasas interpretaciones simplistas. Intentar pasar por unas y otras significaría volver a recorrer el esquema ofrecido, por el doble motivo de que afectan a la mayor parte de sus componentes y también porque parte de las críticas han sido incorporadas por el autor a sus ideas. En cualquier caso, parece claro que las críticas más duras han recaído más sobre su teoría sociolingüística que sobre la educación. Basta recordar en este sentido algunos conocidos títulos de la polémica, como «The logic of nonstandard English», de Lavab; «Language and Class: Critical look at the theories of B. Bernstein», de Rosen, o la re-

22 En Giner, S., and Archer, M. (eds.), Contemporary Europe; Social Structure and Cultural Pattern. London, Routledge and Kegan Paul, 1977. 
ciente y mordaz crítica de Jackson en «The mith of elaborated and restricted codes" ${ }^{23}$.

En sociología de la educación y desde el punto de vista teórico lo más criticado ha sido, como ya apunté, su particular aportación a la disputa de la desigualdad ante la educación. Su teoría lingüística del fracaso, o del déficit lingüístico, es pariente próxima de otras como la del déficit cultural, de la cultura de la pobreza o de las tesis del «hogar adecuado». Por un lado, las imprecisiones de Bernstein hacen a sus puntos de vista prácticamente inseparables de esos otros; por otro, y a pesar de su repudio del optimismo liberal y expresa adscripción a la teoría del conflicto, no se ha librado de la acusación de conservadurismo, como les ha ocurrido a los partidarios de esos otros conceptos próximos. La verdad es que el torbellino ideológico le ha azotado por todas partes, por el lado radical al principio y por el conservador después, siendo así que si Bernstein se ha movido de posición ideológica ha sido hacia el lado radical. Sus abundantes conceptos dicotómicos a veces no han sido suficientemente delimitados, o fueron tomados de los clásicos al margen de la elaboración que les acompañaba, o que les ha seguido. A veces las relaciones entre esos conceptos se establecen de modo simplista, como es el caso entre la pareja orden instrumental-orden simbólico, y la acción burocrática y ritual en las organizaciones educativas. Otras veces se elaboran y complican tanto esas relaciones que se les niega el carácter de teorías, como es el caso ya expuesto de las relaciones entre clases sociales, tipos de familia, códigos lingüísticos y variantes del habla ${ }^{24}$.

Metodológicamente, su alejamiento del soporte empírico ha sido acusado de distintas maneras, desde la ausencia de ejemplos ilustrativos reales, hasta la falta de operacionalización de los conceptos. Paralela ha sido la acusación de ahistoricismo ${ }^{25}$.

Después de haber leído y considerado muchas de las críticas, quisiera hacer un breve comentario sobre el conjunto. Por supuesto, ya el hecho de recibir tanta atención crítica muestra el interés e importancia de sus aportaciones, así como su posición crucial en la materia. De otra parte, el desconsiderar unas ideas porque son criticadas, a veces laboriosamente, implica tener una concepción de lo que es el saber científico de lo más ingenuo e irreal. Más concretamente, insistir en la desviación y abuso teórico de Bernstein, conocidas sus investigaciones empíricas y las de su equipo, puede más bien significar una posición mucho más desviada de sus críticos, esta vez en favor de los simples datos. La creación teórica, la imaginación constructiva, de que

2: Publicados respectivamente en Willdams, F. (ed.), Language and Poverty. London, Markham Press, 1970; ArIstol, Falling Wall Press, 1973; Higher Education Review. Spring, 1974, págs. 65-81.

${ }^{24}$ Stubss, M., Language, Schools and Classrooms. London, Methuen, 1976, página 45 .

2. Cherkaqui, M., "Bernstein and Durkheim: Two Theories of Change in Educational Systems", en Harvard Educational Review, vol. 47, núm. 4, págs. 556-564. 
hace gala Bernstein es, me parece, un recurso de lo más limitativo en la producción científico-social.

La manera sucesiva de presentar sus ideas constituye otro mérito de Bernstein, a la vez que otro motivo de crítica. En las notas, prefacios y posdatas a las sucesivas ediciones de sus trabajos, deja el autor muy claro cuál ha sido el procedimiento y el contexto en el que han surgido, han sido elaboradas, rectificadas o abandonadas sus «hipótesis». Con ellas nos entrega, pues, su «lógica en uso», con frecuencia tan celosamente ocultada por los científicos sociales.

Creo, pues, que respecto de las muchas críticas a Bernstein se puede repetir lo que respecto de su principal inspirador, Durkheim, ha dicho Lukes, que su mayor paradoja está en que cuanto más criticado es, más indispensable se nos hace.

\section{La sociología de la educación para Bernstein}

Con lo dicho hasta aquí creo haber justificado la consideración de que la sociología de la educación de Bernstein está en la encrucijada temática de la actual sociología de la educación. En este punto final trataré de mostrar cómo lo está en la encrucijada teórica, en la confluencia de las diversas corrientes $y$, para algunos, en el arranque de futuros desarrollos ${ }^{26}$.

. Fste apartado podría abrirse señalando una primera paradoja: Bernstein ha cultivado y enriquecido las diversas corrientes de la sociología de la educación, pero ninguna de éstas le considera perteneciente a ella. Diría más, todas le consideran fuera. En efecto, su ubicación y contribución a la corriente funcionalista es evidente y reconocida por el propio autor. También lo son sus críticas y progresivo alejamiento en aspectos importantes. Su contribución al nacimiento de la llamada «nueva» sociología de la educación es antológica. No entramos aquí en su análisis; baste recordar lo dicho de la sociología de la educación de Bernstein en los puntos anteriores y ponerlo en relación con alguna de las caracterizaciones de la «nueva» corriente. Pero también de este enfoque ha sido expulsado, al menos de alguna de sus facciones, que, de colocar sus artículos en lugar central de sus publicaciones, ha pasado a no incluirlos, o incluso a ni siquiera citarle en ellas.

Sus relaciones con los enfoques marxistas tienen algo de parecido. Nadie lo incluirá en sus círculos a pesar de que su análisis parte de, y mantiene como, principal determinante la estructura de clases y sus conflictos; de que progresivamente ha ido incorporando a su análisis temas e instrumentos típicos del enfoque marxista; y a pesar de afirmaciones como ésta: "Trabajo y educación no podrán ser integrados a nivel de principios en una sociedad de clases.»

2* Karabel, J., and Halsey, H., op. cit. Introduction. 
Veamos ahora la otra parte, o mejor, la otra cara de la contradicción: cómo ve Bernstein la sociología de la educación y cómo se ve al margen de las principales corrientes. En uno de sus artículos sobre el estado de la sociología de la educación ${ }^{27}$, inserta a ésta en la sociología general y hace derivar su situación actual de las tensiones de la sociología americana de los años sesenta, como es habitual. Como resultado, la sociología de la educación evoluciona y se diversifica en varios enfoques, que Bernstein reduce a dos, ambos interesados por los mismos problemas (la selección, la igualdad, etc.) pero afrontados de distinta manera: unos se mantendrán en el nivel macrosocial y se interesarán por los componentes de la estructura, y otros bajarán al nivel microsociológico y prestarán atención a la interacción en la educación y al contenido de la misma.

El resultado de la evolución diversificadora es para Bernstein positivo: se afrontan nuevos temas y con nuevos procedimientos; se ofrecen, pues, nuevas opciones al estudioso $\mathrm{y}$, en último término, al ciudadano. Pero Bernstein no está de acuerdo y critica duramente a los distintos enfoques en su proceder y, sobre todo, en sus propias relaciones. Dirá en síntesis: como la teoría y los métodos son débiles en todos los enfoques, sus disputas y enfrentamientos no lo son sobre explicaciones, sino sobre ideologías; todos son capaces de decirnos lo que hay que hacer en sociología de la educación, pero nadie cómo hay que hacerlo; cada enfoque reifica su postura y se convierte en movimiento social o en secta, con rotundas actitudes sobre lo que es aceptable y rechazable, con rígidos mecanismos de admisión o exclusión e incluso con sus propios ritos generacionales.

Adopta, pues, Bernstein, una postura de automarginación, pero no negativa. Al contrario, desde ella plantea una serie de cuestiones que considera de interés para el futuro desarrollo de la sociología de la educación, que, de hecho, tienen el sentido de un programa con pretensiones integradoras. Veamos en síntesis sus propuestas principales:

a) Deben desarrollarse formas de análisis que puedan explicar las relaciones dinámicas entre niveles. Textualmente dirá: «Entre las actividades concretas de negociación de sentidos y las relaciones estructurales que las primeras presuponen.»

b) En las relaciones educación-sociedad sería de interés crucial el poder dar cuenta de las fuerzas y presiones sociales que configuran los diferentes estilos que el conocimiento educativo toma para diferentes tipos de alumnos.

c) Paralelamente, y con la misma perspectiva sobre las fuerzas sociales determinantes, hay que tratar de descubrir los principales estilos or-

27 Bernstein, B., "Sociology and Sociology of Education: a brief account", en Rex, V. (ed.), Approaches to Sociology. London, Routledge and Kegan Paul, 1974, páginas 145-159. 
ganizativos de la educación y sus cambios, que afectan a las relaciones entre los alumnos, entre los profesores y entre alumnos y profesores.

d) Habría que tratar de romper el aislamiento entre los conocimientos escolares y su estructuración, por un lado, y las demás configuraciones simbólicas, dentro y fuera de la educación, por otro. Cita el caso, fuera de la educación, de la música, las canciones y bailes modernos.

Dentro del ámbito educativo sería un ejemplo la conexión con la educación del cuerpo y su condición de sistema de mensajes. (En el ejemplo concreto habría que encontrar los elementos subyacentes al sucesivo paso del entrenamiento físico, a la educación física y, más recientemente, a la expresión dinámica.)

Aunque sea esquemáticamente, creo haber mostrado en lo que antecede lo que llamo encrucijada teórica de Bernstein. Pero, como dije al principio, ésta tiene otra manifestación, de segundo grado si se quiere, pero nada despreciable. Me refiero a su peculiar posición entre las principales manifestaciones nacionales o continentales de la sociología de la educación, peculiaridades ciertas e incluso importantes, aunque a primera vista difíciles de explicar en la era de la información y las comunicaciones.

Pues bien, Bernstein es un sociólogo por supuesto y ante todo británico, es europeo de una manera peculiar y no puede renunciar a la referencia americana. Lo primero es evidente; el desarrollo de su sociología de la educación es impensable fuera del contexto educativo y político de su país. Sus relaciones con la sociología de la educación continental es peculiar en varios sentidos: los clásicos le sirven de inspiración (Durkheim en concreto es citado expresamente en casi todos sus trabajos); de habla inglesa al fin, parece ignorar que se escriba sociología en otros idiomas, hasta su estancia en París en 1975, donde reconoce, con cierta mala conciencia, que al fin se entera de los trabajos del Centro de Sociología Europeo porque pueden explicárselos en inglés; en sus posteriores trabajos la aproximación a la sociología francesa, al menos la de este grupo, es intensa e incluso llega a hacer breves citas en francés y aludir al Durkheim entonces no traducido, el de «L'évolution pédagogique en France».

Finalmente, sus tensiones y ambivalencias con Norteamérica, de donde le han llegado muy duras críticas, son evidentes. Llega a considerar a la sociología británica parásita de la americana, que, como en los tiempos de la colonia, dirá, «sigue facilitando ricas telas para las nuevas ropas del emperador», e incluso llega a descubrir a los ingleses los clásicos europeos.

He tratado de presentar, por fuerza muy esquemáticamente, varios aspectos de la que he llamado encrucijada de Bernstein en sociología de la educación y principalmente el aspecto temático y el teórico de dicha encrucijada. Quedan otros también de gran interés. Terminaré aludiendo a la indudable 
encrucijada subyacente, la personal, que habría quedado descubierta si hubiera habido espacio para integrar sus ideas en el contexto social y biográfico en que han surgido. Esta encrucijada, más concreta y honda, se manifiesta en muchos pasajes de su obra. Al reconsiderar, por ejemplo, el tema del déficit lingüístico, dirá: «Mi posición intelectual es nada confortable, como tampoco es confortable la realidad» ${ }^{28}$. Y al final del artículo citado sobre la sociología de la educación, y después de criticar duramente el proceder de las diferentes escuelas, acepta el pluralismo que significan y aclara tajantemente que en ningún caso su «postura personal es puramente estética, no está hecha de una objetividad espúrea, ni mucho menos es insensible a las violaciones de nuestro contexto político» ${ }^{29}$.

${ }^{29}$ Bernstein, B., Sociology and the Sociology of Education, op. cit., págs. 157-158. 